\title{
NEUROPSYCHOLOGICAL AND NEUROIMAGING EXAMINATIONS OF SELF-REPORTED SLEEP QUALITY IN ALCOHOL USE DISORDER WITH AND WITHOUT KORSAKOFF'S SYNDROME
}

Alice Laniepce, MSc. ${ }^{1}$, Shailendra Segobin, PhD. ${ }^{1}$, Coralie Lannuzel, MSc. ${ }^{1}$, Céline Boudehent, MSc. ${ }^{1,2}$, Ludivine Ritz, PhD. ${ }^{1}$, Laurent Urso, MD. ${ }^{3}$, François Vabret, MD. ${ }^{1,2}$, Francis Eustache, PhD. ${ }^{1}$, Hélène Beaunieux, $\mathrm{PhD} .{ }^{1}$, Géraldine Rauchs, $\mathrm{PhD}^{1 *}$., Anne-Lise Pitel, $\mathrm{PhD}^{1 *}$.

$$
\text { *: equally contributed to this work }
$$

1 : Normandy Univ, UNICAEN, PSL Université, EPHE, INSERM, U1077, CHU de Caen, GIP Cyceron, Neuropsychologie et Imagerie de la Mémoire Humaine, Caen, France.

${ }^{2}$ : Addiction department, Centre Hospitalier Universitaire de Caen, France.

${ }^{3}$ : Addiction department, Centre Hospitalier de Roubaix, France.

\section{Corresponding author:}

Pitel Anne-Lise

Centre Cyceron, Campus Jules Horowitz

Boulevard Henri Becquerel, BP 5229

14074 Caen Cedex 5, FRANCE

+33(0)2 31470125

pitel@cyceron.fr

Number of words in the abstract: 297

Number of words in the body of the manuscript: 4950

Number of figures: $\mathbf{5}$; Number of color figures: $\mathbf{5}$

Number of tables: $\mathbf{3}$

The authors declare no conflicts of interest. This work was supported by the French National Institute for Health and Medical Research (INSERM), the French National Agency for Research (ANR), and Conseil Régional de Basse-Normandie. Alice Laniepce's doctoral fellowship was co-funded by European Union in the framework of the ERDF-ESF operationnal programme 2014-2020 and Lundbeck Society. 
Background: Alcohol Use Disorder (AUD) patients without Korsakoff's syndrome (KS) report a variable self-rated sleep quality. Their ability to accurately judge their sleep quality may be related to their alcohol-related cognitive deficits and brain damage. KS patients, who present severe brain dysfunction, may be cognitively unable to judge their sleep quality. The aim of the present study is to examine in AUD and KS patients, whether the absence of sleep complaint is associated with altered brain structure and impaired cognitive abilities within specific cerebral networks.

Methods: An assessment of subjective sleep quality was conducted in 20 healthy controls, 37 AUD and $17 \mathrm{KS}$ patients. Patients were first pooled together and then classified into two groups (nocomplaint $^{\mathrm{AUD}+\mathrm{KS}}$ and complaint ${ }^{\mathrm{AUD}+\mathrm{KS}}$ ) according to the total PSQI score. Cognitive scores, gray matter volume (GM) and white matter (WM) integrity were compared between these two groups, and then in AUD and KS patients separately.

Results: Poor sleep quality was reported by $70 \%$ of AUD and $18 \%$ of KS patients. Compared to controls, both no-complaint ${ }^{\mathrm{AUD}+\mathrm{KS}}$ and complaint ${ }^{\mathrm{AUD}+\mathrm{KS}}$ presented cortical and subcortical alterations as well as episodic memory deficits, which were more severe in patients without sleep complaint. Only no-complaint ${ }^{\mathrm{AUD}+\mathrm{KS}}$ presented executive deficits. Then, considering the clinical diagnosis, GM volume in fronto-temporal regions, WM integrity and executive functions were affected to the same extent in AUD and KS without sleep complaint.

Conclusion: Our results confirm the high prevalence of sleep complaint in AUD patients and the rare complaint in KS patients. In AUD and KS patients, the absence of sleep complaint may not indicate good sleep quality but rather reflect executive deficits and fronto-thalamic damage. Alcohol-related cognitive deficits may indeed alter the ability to self-evaluate sleep quality, suggesting that the use of sleep questionnaire should be considered with caution in patients with executive deficits.

Keywords: Alcohol Use Disorder; Korsakoff's syndrome; Neuropsychology; Neuroimaging; Subjective sleep assessment 
Alcohol-related neurological disorders exist principally in two clinical forms that can be distinguished based on the severity of brain dysfunction (Zahr, 2014) and cognitive deficits (Oscar-Berman et al., 2014). The more severe clinical form is the Korsakoff's syndrome (KS), which is a neurological complication related to the combination of chronic and excessive alcohol consumption and thiamine deficiency. KS is described as a severe and profound amnesia potentially associated with executive dysfunction. Alcohol Use Disorder without KS (AUD) is also characterized by episodic memory deficits and executive dysfunction, from mild to moderate in most cases up to severe in some patients at risk for KS (Pitel et al., 2008).

Chronic and heavy alcohol consumption is not only associated with neuropsychological impairments but also with major sleep disorders. Sleep disturbances are frequently present in recently detoxified AUD patients (Angarita et al., 2016) with a variable sleep complaint reported by 36 to $72 \%$ of the population. Such variability can be explained by the AUD patients' clinical features (the criteria used to diagnose AUD or alcohol abuse, the length of sobriety at the time of the sleep assessment), as well as the absence of standard definitions and measurements of sleep complaint (different sleep questionnaires with, for example, different time frames; Brower, 2001; Stein and Friedmann, 2005). While objective sleep quality seems affected in KS patients (Lairie and Pottier, 1979; Martin et al., 1986), only one study considered their subjective sleep perception (Lairie and Pottier, 1979) and suggested that KS patients would report sleeping well. This seemingly absent sleep complaint in KS patients may be related to their characteristic impaired self-awareness (Arts et al., 2017).

Even in absence of KS, altered abilities to accurately self-evaluate have been described in AUD patients regarding neuropsychological performance (overall cognitive abilities, episodic memory decoding of facial emotions) and daily recall of alcohol consumption (Kornreich, 2002; Le Berre et al., 2010; Lincoln et al., 2011; Rinn et al., 2002; Walvoort et al., 2016). The variability in the sleep complaint prevalence observed in AUD patients may thus be related to their ability to self-assess their sleep quality. Indeed, an accurate subjective sleep evaluation requires efficient episodic memory abilities to recall recent sleep periods and executive functions to interpret internal and physical states, to quantify sleep duration and to respond to a written sleep questionnaire. AUD patients with episodic 
memory impairments and executive dysfunctions may not be cognitively able to correctly evaluate their sleep quality, just as it may be the case in KS patients.

The objective of the present study is to investigate subjective sleep quality in KS and recently detoxified AUD patients using a validated sleep questionnaire. We aim at examining whether the absence of sleep complaint is associated with altered brain structure and cognitive abilities within cerebral networks involved in episodic memory and executive functions. First, we hypothesize that most KS patients do not complain about their sleep while most AUD patients do. Second, we hypothesize that KS and AUD patients without sleep complaint present more severe alterations of the brain networks involved in episodic memory and executive functions than patients who complain about their sleep. Third, we hypothesize that this profile of executive dysfunction and associated brain alterations is similar in KS and AUD without sleep complaint. 


\section{MATERIALS AND METHODS}

\subsection{Participants}

Seventy-four participants were included in this study: 54 patients with AUD or KS (37 AUD patients and $17 \mathrm{KS}$ patients) and 20 healthy controls (HC). None of them had a history of neurological pathology (except diagnosis of KS), endocrinal nor other infectious diseases, depression (assessed using the Beck Depression Inventory (Beck et al., 1961) nor other forms of substance use disorder (except tobacco). All participants were informed about the study approved by the local ethics committee of Caen University Hospital (CPP Nord Ouest III, no. IDRCB: 2011-A00495-36) prior to their inclusion and provided their written informed consent. For KS, informed consent was collected from guardians or caregivers as well as from the patients themselves.

Clinicians recruited AUD patients while they were receiving withdrawal treatment as inpatients at Caen University Hospital. AUD patients met "alcohol-dependence" criteria according to the DSM-IV (American Psychiatric Association (APA), 2000) and "alcohol use disorder" according to the DSM-5 (American Psychiatric Association, 2013) for at least 5 years. At inclusion and evaluation, none of them presented physical symptoms of alcohol withdrawal as assessed by the Cushman's scale (Cushman et al., 1985) and were under medication by benzodiazepines. Alcohol history of the AUD patients is described in Table 1.

KS were recruited as inpatients at Caen University Hospital $(n=9)$ and in a nursing home (Maison Vauban, Roubaix, France; n=8). All KS patients were diagnosed with reference to the clinical DSMIV criteria of "amnesia due to substance abuse" and "major neurocognitive disorders, confabulatory type, persistent" according to the DSM-5. All KS patients had a history of heavy drinking, but it was difficult to obtain accurate information about their alcohol intake due to their amnesia. The case of each patient was examined by a multidisciplinary team made up of specialists in cognitive neuropsychology and behavioural neurology. A detailed neuropsychological examination enabled the diagnosis of all KS patients presenting disproportionately severe episodic memory disorders compared to other cognitive functions (Table 1). Clinical and neuroimaging investigations ruled out other possible causes of memory impairments (particularly focal brain damage). 
HC were recruited locally and to match the demographics of the AUD patients. They were interviewed with the AUDIT to ensure that they did not meet the criteria for alcohol abuse (AUDIT $<7$ for men and $<6$ for woman (Gache et al., 2005)). None of the controls had a Beck Depression Inventory (BDI) $>29$ (Beck et al., 1961), an MMSE score < 26 (Folstein et al., 1975), nor sleep complaint (Pittsburg Sleep Quality Index $\leq$ 5; Buysse et al., 1989).

-Insert Table 1-

AUD and HC were age-, sex- and education-matched $(\mathrm{p}=0.31, \mathrm{p}=0.42$ and $\mathrm{p}=0.31$ respectively). KS differed from both HC and AUD in age $(\mathrm{p}<0.001)$ and only from HC $(\mathrm{p}=0.03)$ for education. The sex ratio was also different in the KS group from that in the $\mathrm{HC}(\mathrm{p}=0.01)$ and AUD groups $(\mathrm{p}=0.04)$. There was no difference on BMI among the three groups (Table 1).

\subsection{Subjective assessment of sleep quality}

All participants completed the Pittsburg Sleep Quality Index (PSQI; Buysse et al., 1989) during the neuropsychological examination. The PSQI is a 19-item self-assessment questionnaire that allows a measure of sleep quality and disturbances over the last month. Seven components are evaluated ranging from 0 to 3: subjective sleep quality, sleep latency, sleep duration, habitual sleep efficiency, sleep disturbances, use of sleeping medication and daytime dysfunction. The total score ranges from 0 (indicating no difficulty) to 21 (major sleep difficulties). As recommended, a cut-off score of 5 was used to indicate a significant sleep complaint.

Based on the total PSQI score, patients (AUD and KS) were divided into 2 subgroups:

(i) No-complaint ${ }^{\text {AUD+KS }}$ patients corresponding to patients who did not complain about their sleep (i.e., PSQI score $\leq$ 5)

(ii) Complaint ${ }^{\mathrm{AUD}+\mathrm{KS}}$ patients corresponding to patients who complained about their sleep (i.e., PSQI score > 5).

\subsection{Neuropsychological examination}

For executive functions, a composite score was created including performance on three tests assessing manipulation of information (verbal backward spans of the WAIS-III (Wechsler, 1997)), inhibition 
151 (Stroop Test (Stroop, 1935), time in seconds needed to complete the interference condition minus time

152 needed for the denomination condition) and mental flexibility (Modified Card Sorting Test (Cianchetti

153 et al., 2005), number of perseverative errors).

154 Episodic memory was examined through the sum of the five free-recalls of the French version of the 155 California Verbal Learning Test (CVLT ; Van der Linden et al., 2004).

156 Neuropsychological data were then transformed into z-scores using the mean and standard deviation 157 obtained from the healthy controls. The sign of all variables for which high scores were in the 158 impaired direction (such as completion time or number of errors) were reversed so that all the z-scores 159 had the same direction: the higher the z-score, the better the performance. Thus, all cognitive and 160 motor variables were on the same scale. We computed a global composite score corresponding to the mean of the 3 z-scores (manipulation of information, inhibition and mental flexibility) for executive 162 functions.

This neuropsychological examination showed graded effects of deficits for all evaluated cognitive functions with KS presenting more severe impairments than AUD patients (all $\mathrm{p}$ values $<0.001$, Table $1651)$.

167 Brain imaging examinations were conducted in $15 \mathrm{HC}, 20$ AUD and $17 \mathrm{KS}$ patients within the same 168 week as the neuropsychological assessment and the sleep questionnaire.

169 A high-resolution T1-weighted anatomical image was acquired for each subject on a Philips Achieva 3T scanner using a three-dimensional fast-field echo sequence (sagittal; repetition time, $20 \mathrm{~ms}$; echo time, $4.6 \mathrm{~ms}$; flip angle, $10^{\circ}$; 180 slices; slice thickness: $1 \mathrm{~mm}$; field of view, 256 x $256 \mathrm{~mm}^{2}$; matrix, 256 x 256). Regarding Diffusion Tensor Imaging (DTI), 70 slices (thickness: $2 \mathrm{~mm}$, no gap) were acquired axially using a diffusion weighted imaging spin echo sequence (32 directions at $b=1000$ $\mathrm{s} / \mathrm{mm}^{2}$, repetition time $=10000 \mathrm{~ms}$; echo time $=82 \mathrm{~ms}$; flip angle $=90^{\circ}$, field of view $=224 \times 224$ $\mathrm{mm}^{2}$, matrix $=112 \times 112$ and in plane resolution of $2 \times 2 \mathrm{~mm}^{2}$; one no-diffusion weighted image at $\mathrm{b}=$ $0 \mathrm{~s} / \mathrm{mm}^{2}$ was also acquired). 
The volumetric MRI data were analyzed using the Statistical Parametric Mapping software (SPM12; Wellcome Department of Cognitive Neurology, Institute of Neurology, London, UK). Preprocessing steps included segmentation of the MRI data into gray matter (GM) and spatial normalization to the Montreal Neurological Institute $(\mathrm{MNI})$ template $\left(\right.$ voxel size $=1.5 \mathrm{~mm}^{3}$, matrix $\left.=121 \times 145 \times 121\right)$. The normalized GM images were modulated by the Jacobian determinants to correct for non-linear warping only so that the resulting brain volumes were corrected for brain size. The resulting images were smoothed by a Gaussian kernel of $8 \mathrm{~mm}$ full-width-at-half-maximum (FWHM). GM volume density reflects cerebral macrostructure and numerically corresponds to the mean gray matter per unit volume for each significant cluster.

The diffusion-weighted images (DWI) were first preprocessed to create Fractional Anisotropy (FA) images using the FSL Diffusion Toolbox (FDT; http://fsl.fmrib.ox.ac.uk/fsl/ fslwiki/FDT) that is part of FSL 5.0 toolbox for medical image analysis (Smith et al., 2004). Briefly, for each subject, the 32 DWI images were first corrected for distortions due to Eddy currents and aligned to the $b=0 \mathrm{~s} / \mathrm{mm}^{2}$ image using rigid-body registration for motion correction (Jenkinson et al., 2002). FA images were then created by fitting a tensor model to the diffusion images. Individual FA data were aligned into MNI space using the nonlinear registration tool (FNIRT), which uses a b-spline representation of the registration warp field (Rueckert et al., 1999). The resulting FA maps were resliced to matrix size of $182 \times 218 \times 182$ and voxel size of $1 \mathrm{~mm}^{3}$ and smoothed to $6 \mathrm{~mm}$ FWHM prior to voxel-based statistical analyses. Numerically, FA values vary between 0 and 1 . Generally, the higher the FA value, the better the microstructural integrity of the fiber within that voxel. FA is assumed to be a structural biomarker that depicts WM disruption involving myelin, cytoskeleton, and the axons' microtubule system (Pfefferbaum et al., 2006).

The GM mask was obtained taking the unmodulated GM images of healthy controls (HC) normalized to the MNI space, averaging them and thresholding the resultant mean image at 0.5 . The white matter (WM) mask was obtained by taking the FA maps of healthy controls normalized to the MNI space, averaging them and thresholding the resultant mean image at 0.3 . The resulting GM and WM masks were applied respectively to GM and WM data analyses. 


\subsubsection{Prevalence of sleep complaint in AUD and KS patients}

207 We first described the prevalence, severity and nature of the sleep complaint in the HC, AUD and KS patients using $\mathrm{Chi}^{2}$ tests and ANCOVAs (age, gender and Body Mass Index (BMI) used as covariates) when appropriate.

\subsubsection{Pattern of cognitive alterations according to sleep quality}

Then, we pooled the AUD and KS patients together and conducted ANCOVAs (using age, gender and BMI as covariates) followed by post-hoc comparisons (Tukey's tests) on neuropsychological data to compare $\mathrm{HC}$, no-complaint ${ }^{\mathrm{AUD}+\mathrm{KS}}$ and complaint ${ }^{\mathrm{AUD}+\mathrm{KS}}$ patients.

214 We also investigated whether this effect was driven by the results obtained in a specific clinical group

215 by comparing $\mathrm{HC}$, complaint ${ }^{\mathrm{AUD}}$, no-complaint ${ }^{\mathrm{AUD}}$ and no-complaint ${ }^{\mathrm{KS}}$ patients using ANCOVAs with age, gender and BMI as covariates. Given the sample size of the complaint ${ }^{\mathrm{KS}}$ group $(\mathrm{N}=3)$, these patients were not included in the statistical analysis (Table 2).

\subsubsection{Pattern of brain alterations according to sleep quality}

Voxel-based ANCOVAs were conducted in SPM12, with age, gender and BMI as covariates, to compare $\mathrm{HC}$, no-complaint ${ }^{\mathrm{AUD}+\mathrm{KS}}$ and complaint ${ }^{\mathrm{AUD}+\mathrm{KS}}$ patients on GM volume and WM integrity (FA values). Results are reported at $\mathrm{p}<0.001$ (uncorrected for multiple comparisons) with a minimal cluster size (k) of 60 voxels $\left(200 \mathrm{~mm}^{3}\right)$.

Once again, to ensure that the effect was not only due to the presence of KS patients in the clinical sample, average signal values within significant clusters were extracted and post hoc tests (Tukey's tests) were conducted to compare $\mathrm{HC}$, complaint ${ }^{\mathrm{AUD}}$, no-complaint ${ }^{\mathrm{AUD}}$ and no-complaint ${ }^{\mathrm{KS}}$ patients. the statistical analysis. 
229 Significant clusters of GM were labeled using the Harvard-Oxford cortical and subcortical structural 230 atlases implemented in FSL (https://fsl.fmrib.ox.ac.uk/fsl/fslwiki/Atlases). WM regions were manually 231 labeled using the MRI Atlas of Human white matter (Oishi et al., 2011).

232 


\section{RESULTS}

\subsection{Prevalence of sleep complaint in AUD and KS patients.}

235

236

237

238

Prevalence of sleep complaint: Based on the PSQI total score, poor sleep quality (PSQI total score > 5) was significantly more frequently reported in AUD patients (70.3\%) than in KS patients $(17.6 \%)$ and HC (Table 3, Fig 1).

Severity of sleep complaint: The ANCOVA revealed a significant effect of group on the PSQI total score $(\mathrm{F}(2,68)=26,63 ; \mathrm{p}<0.0001 ;$ Table 3$)$. AUD patients had higher scores than KS patients $(p<0.0001)$ and HC $(p<0.0001)$, these two latter groups being comparable $(p=0.93)$.

Nature of sleep complaint: ANCOVAs conducted on each PSQI subcomponent revealed significant effects of group (all F-values are reported in Table 3). Compared to HC, AUD patients reported poor subjective sleep quality $(\mathrm{p}<0.004)$, longer sleep latency $(\mathrm{p}=0.03)$ and sleep disturbances $(\mathrm{p}=0.001)$, more frequent use of sleeping medication $(\mathrm{p}=0.03)$, altered sleep efficiency $(\mathrm{p}=0.01)$ and daytime dysfunction $(\mathrm{p}<0.03)$. No difference was observed between $\mathrm{HC}$ and $\mathrm{KS}$ patients (all $\mathrm{p}$ values $>0.05$ ). Compared to KS patients, AUD patients reported significantly poor subjective sleep quality ( $\mathrm{p}=0.003$ ), shorter sleep duration $(\mathrm{p}=0.005)$, sleep disturbances $(\mathrm{p}=0.0009)$ and daytime dysfunction $(\mathrm{p}=0.008$; Table 3).

- Insert Figure 1 and Table 3 -

\subsection{Pattern of cognitive alterations according to sleep quality.}

\subsubsection{HC vs no-complaint ${ }^{A U D+K S}$ patients vs complaint ${ }^{A U D+K S}$ patients}

The ANCOVAs revealed significant effects of group ( $\mathrm{HC}$ vs no-complaint ${ }^{\mathrm{AUD}+\mathrm{KS}}$ vs complaint ${ }^{\mathrm{AUD}+\mathrm{KS}}$ patients) for executive $(F(2,68)=7.69 \mathrm{p}=0.0009)$ and episodic memory scores $(\mathrm{F}(2,66)=6.21 \mathrm{p}=0.003)$.

Concerning executive functions, post-hoc comparisons showed that complaint ${ }^{\mathrm{AUD}+\mathrm{KS}}$ patients were comparable to $\mathrm{HC}(\mathrm{p}=0.20)$, contrary to no-complaint ${ }^{\mathrm{AUD}+\mathrm{KS}}$ patients who presented lower executive performance compared to both $\mathrm{HC}(\mathrm{p}=0.0001)$ and complaint ${ }^{\mathrm{AUD}+\mathrm{KS}}$ patients $(\mathrm{p}=0.008$; Fig $2 \mathrm{~A})$. 
257 For episodic memory, graded effects were observed with no-complaint ${ }^{\mathrm{AUD}+\mathrm{KS}}$ patients showing lower 258 performance than complaint ${ }^{\mathrm{AUD}+\mathrm{KS}}$ patients, these latter showing also reduced performance compared 259 to $\mathrm{HC}$ (all $\mathrm{p}$ values $<0.01$; Fig $2 \mathrm{~A}$ ).

\subsubsection{HC vs complaint ${ }^{A U D}$ patients vs no-complaint ${ }^{A U D}$ patients vs no-complaint ${ }^{K S}$ patients}

The ANCOVAs revealed a significant effect of group for executive $(F(3,64)=5.31 \mathrm{p}=0.002)$ and episodic memory scores $(\mathrm{F}(3,62)=20.31 \mathrm{p}<0.0001)$.

Concerning executive functions, post-hoc comparisons showed that complaint ${ }^{\mathrm{AUD}}$ patients presented similar performance as $\mathrm{HC}(\mathrm{p}=0.51)$ and no-complaint ${ }^{\mathrm{AUD}}$ patients $(\mathrm{p}=0.23)$. No-complaint ${ }^{\mathrm{AUD}}$ patients and no-complaint ${ }^{\mathrm{KS}}$ patients had significantly lower executive performance than $\mathrm{HC}$ ( $\mathrm{p}=0.02$ and $p=0.001$ respectively), but did not differ from each other $(p=0.94 ;$ Fig $2 B)$.

Regarding episodic memory, post-hoc comparisons showed that no-complaint ${ }^{\mathrm{AUD}}$ patients and complaint $^{\mathrm{AUD}}$ patients presented similar performance as $\mathrm{HC}(\mathrm{p}=0.47$ and $\mathrm{p}=0.05$ respectively) and did not differ from each other $(\mathrm{p}=0.92)$. No-complaint ${ }^{\mathrm{KS}}$ patients performed significantly lower than the three other groups ( $\mathrm{p}=0.0001$ for all comparisons; Fig 2B).

\section{- Insert Figure 2 -}

\subsection{Pattern of brain alterations according to sleep quality.}

\subsubsection{Gray-matter volume}

Compared to $\mathrm{HC}$, no-complaint ${ }^{\mathrm{AUD}+\mathrm{KS}}$ patients had significantly lower $\mathrm{GM}$ volume in frontal and prefrontal areas, insula, lateral and medial temporal cortices (including the hippocampus and parahippocampal gyrus), cingulate and occipital cortices, but also in subcortical regions including the thalamus, putamen and caudate nuclei, and in the cerebellum ( $p<0.001$, uncorrected, $k=60)$. These results remained significant after correction for multiple comparisons but with smaller cluster size (Family Wise Error (FWE), p<0.05; Fig 3A).

Compared to $\mathrm{HC}$, complaint ${ }^{\mathrm{AUD}+\mathrm{KS}}$ patients had lower $\mathrm{GM}$ volume in frontal and prefrontal areas, insula, lateral and medial cortices (including the hippocampus and parahippocampus gyrus), cingulate and occipital cortices, but also in subcortical regions including the thalamus, putamen and caudate 
nuclei, and in the cerebellum ( $\mathrm{p}<0.001$, uncorrected, $\mathrm{k}=60$ ). After correction for multiple comparisons, only the bilateral precentral gyrus (clusters encompass the postcentral gyrus), the right insula, the bilateral lingual gyrus, the bilateral cuneus and the left thalamus remained significant (FWE, $\mathrm{p}<0.05$; Fig 3B).

As shown in Figure 4A, compared to complaint ${ }^{\mathrm{AUD}+\mathrm{KS}}$ patients, no-complaint ${ }^{\mathrm{AUD}+\mathrm{KS}}$ patients had significantly lower GM volume in frontal and prefrontal areas (including the right middle frontal gyrus, the median frontal gyrus, bilateral precentral gyrus, bilateral inferior frontal gyrus, left superior frontal gyrus), middle cingulate gyrus, bilateral precuneus, the temporal pole, the occipital gyrus and the left thalamus $(\mathrm{p}<0.001$ uncorrected, $\mathrm{k}=60)$. These results did not remain significant after correction for multiple comparisons. The reverse comparison did not reveal any significant difference.

From this comparison (complaint ${ }^{\mathrm{AUD}+\mathrm{KS}}$ patients $>$ no-complaint ${ }^{\mathrm{AUD}+\mathrm{KS}}$ patients), signal values within each cluster were extracted and compared between the different subgroups (HC, complaint ${ }^{\mathrm{AUD}}$ patients, no-complaint ${ }^{\mathrm{AUD}}$ patients and no-complaint ${ }^{\mathrm{KS}}$ patients).

Compared to $\mathrm{HC}$, no-complaint ${ }^{\mathrm{AUD}}$ patients and no-complaint ${ }^{\mathrm{KS}}$ patients showed significantly lower values for all extracted clusters $(\mathrm{p}<0.001)$. Compared to $\mathrm{HC}$, complaint ${ }^{\mathrm{AUD}}$ patients presented significantly lower GM volume in all clusters except in the medial prefrontal cortex $(\mathrm{p}=0.06)$. Compared to complaint ${ }^{\mathrm{AUD}}$ patients, no-complaint ${ }^{\mathrm{AUD}}$ patients exhibited lower values only for the middle frontal gyrus $(\mathrm{p}=0.002)$, the inferior frontal gyrus $(\mathrm{p}=0.02)$, the superior frontal gyrus $(\mathrm{p}=0.03)$, the temporal pole $(p=0.02)$ and the occipital cortex $(p=0.003)$. Compared to complaint ${ }^{\text {AUD }}$ patients, nocomplaint $^{\mathrm{KS}}$ patients exhibited significant GM atrophy for all extracted clusters (all $\mathrm{p}$ values $<0.05$ ). No difference was observed between no-complaint ${ }^{\mathrm{AUD}}$ patients and no-complaint ${ }^{\mathrm{KS}}$ ( $\mathrm{p}>0.05$; Fig 4B).

Partial Pearson's correlations adjusted for age, sex and BMI were conducted in the two groups of patients pooled together (no-complaint ${ }^{\mathrm{AUD}+\mathrm{KS}}$ patients vs complaint ${ }^{\mathrm{AUD}+\mathrm{KS}}$ patients) between regional volumes in all extracted clusters on the one hand and neuropsychological performance on the other hand. We found significant relationships only between the thalamus $(r=0.61, p=0.005)$, the temporal pole $(\mathrm{r}=0.52, \mathrm{p}=0.02)$, the lingual gyrus $(\mathrm{r}=0.47, \mathrm{p}=0.04)$ and episodic memory results as well as 
between the volume in the middle frontal and precentral gyri and the executive performance $(\mathrm{r}=0.60$, $\mathrm{p}=0.006 ; \mathrm{r}=0.50, \mathrm{p}=0.02$ respectively) in no-complaint ${ }^{\mathrm{AUD}+\mathrm{KS}}$ patients. There was no significant correlation in the complaint ${ }^{\mathrm{AUD}+\mathrm{KS}}$ patients between cerebral volume and cognitive functions.

\subsubsection{White-Matter integrity}

315

Compared to $\mathrm{HC}$, no-complaint ${ }^{\mathrm{AUD}+\mathrm{KS}}$ patients had significantly lower FA values, indicating an alteration of WM, in a large set of fibers including the corpus callosum, the anterior corona radiata, the anterior limb of the internal capsule, the cingulum, the middle cerebellar peduncle and the fornix. These results remained significant after correction for multiple comparisons but with smaller cluster size (FWE, $\mathrm{p}<0.05$; Fig 3C).

The same pattern of white matter abnormalities was observed in complaint ${ }^{\mathrm{AUD}+\mathrm{KS}}$ patients compared with HC. These results did not remain significant after correction for multiple comparisons (Fig 3D).

As shown in Figure $5 \mathrm{~A}$, compared to complaint ${ }^{\mathrm{AUD}+\mathrm{KS}}$ patients, no-complaint ${ }^{\mathrm{AUD}+\mathrm{KS}}$ patients had significantly lower FA values in the anterior and superior parts of the corana radiata, the bilateral cingulum, the inferior and superior parts of the longitudinal fasciculus, the right fornix (encompassing the cerebral peduncle and the internal capsule), the bilateral external capsule, the left anterior thalamic radiation, and the white matter within the post-central gyrus, the angular gyrus, the superior frontal gyrus and the precuneus $(\mathrm{p}<0.001$, uncorrected, $\mathrm{k}=60)$. These results did not remain significant after correction for multiple comparisons. The reverse comparison did not reveal any significant difference.

From this comparison (complaint ${ }^{\mathrm{AUD}+\mathrm{KS}}$ patients $>$ no-complaint ${ }^{\mathrm{AUD}+\mathrm{KS}}$ patients), signal values were extracted within each significant cluster and compared between subgroups (HC, complaint ${ }^{\mathrm{AUD}}$ patients, no-complaint ${ }^{\mathrm{AUD}}$ patients and no-complaint ${ }^{\mathrm{KS}}$ patients). Compared to $\mathrm{HC}$, i) complaint ${ }^{\mathrm{AUD}}$ patients presented lower FA values in the anterior thalamic radiation $(\mathrm{p}=0.008)$; ii) no-complaint ${ }^{\mathrm{AUD}}$ patients exhibited lower FA values in all extracted clusters $p<0.01$, except for the white matter in the postcentral gyrus $(p=0.74)$ and the superior longitudinal fasciculus $(p=0.07)$; and iii) no-complaint ${ }^{\mathrm{KS}}$ patients showed lower FA values in all clusters $(\mathrm{p}<0.001)$. Compared to complaint ${ }^{\text {AUD }}$ patients, nocomplaint $^{\mathrm{AUD}}$ patients presented lower FA values in all extracted clusters except in the left anterior 
337 thalamic radiation $(\mathrm{p}=0.08)$, the external capsule $(\mathrm{p}=0.22)$ and the white matter of the supramarginal 338 gyrus $(\mathrm{p}=0.06)$, the precuneus $(\mathrm{p}=0.06)$ and the postcentral gyrus $(\mathrm{p}=0.39)$. No difference was found 339 between no-complaint ${ }^{\mathrm{AUD}}$ patients and no-complaint ${ }^{\mathrm{KS}}$ patients (Fig 5B).

340 Partial Pearson's correlations adjusted for age, sex and BMI were conducted in the two groups of 341 patients pooled together (no-complaint ${ }^{\mathrm{AUD}+\mathrm{KS}}$ patients vs complaint ${ }^{\mathrm{AUD}+\mathrm{KS}}$ patients) between regional

342 FA values in all extracted clusters on the one hand and neuropsychological performance on the other 343 hand.

344 In complaint ${ }^{\mathrm{AUD}+\mathrm{KS}}$ patients, we found significant relationships between FA values of the WM part of 345 the angular gyrus and episodic memory performance $(\mathrm{r}=0.69, \mathrm{p}=0.02)$. In no-complaint ${ }^{\mathrm{AUD}+\mathrm{KS}}$ patients, 346 we found significant relationships between the anterior thalamic radiation $(r=0.62, p=0.008)$, the 347 external capsule $(\mathrm{r}=0.60, \mathrm{p}=0.01)$, the inferior longitudinal fasciculus $(\mathrm{r}=0,50, \mathrm{p}=0.04)$, the bilateral 348 cingulum $(r=0.72, p=0.001)$, the anterior corona radiata $(r=0.61, p=0.009)$ and executive functions. We 349 also showed significant relationships between the bilateral cingulum $(\mathrm{r}=0.60, \mathrm{p}=0.01)$, the superior 350 longitudinal fasciculus $(\mathrm{r}=0.52, \mathrm{p}=0.03)$ and episodic memory. 


\section{DISCUSSION}

354 The aim of the present study was to investigate, in recently detoxified AUD and KS patients, whether self-estimated sleep quality is related to cognitive functioning and brain integrity.

First, in agreement with previous studies, we observed a high prevalence of sleep complaint in recently detoxified AUD patients (Angarita et al., 2016; Chakravorty et al., 2016). We showed that, compared to HC, AUD patients with sleep complaint present a pattern of macrostructural brain damage in frontal and temporal cortices, as well as cingulate gyrus and thalamus, known to be affected by heavy and chronic alcohol consumption (Zahr, 2014). Interestingly, all these regions are involved in the generation and maintenance of both NREM and REM sleep rhythms (Maquet et al., 1996; Massimini et al., 2004; Murphy et al., 2009; Schabus et al., 2007). Moreover, reduced GM volume in the frontal cortex have been related to higher sleep complaint (Sexton et al., 2014). AUD patients with sleep complaint also had lower FA values in the anterior thalamic radiation, in accordance with a recent study showing that altered WM tracts were associated with higher sleep complaint in older adults (Sexton et al., 2017). Thus, in this group of patients who complain about their sleep, poor selfrated sleep quality may be related to the objective sleep alterations expected given their pattern of brain dysfunction (Chakravorty et al., 2016).

Our study showed that most of the KS patients (14 out of 17) reported sleeping as well as healthy controls. To the best of our knowledge, our study is the first to investigate, in KS patients, sleep complaint using a validated and widely used sleep questionnaire (Buysse et al., 1989) in KS patients.

Our findings are not in accordance with polysomnography studies showing objective sleep alterations in KS patients (Martin et al., 1986), highlighting the frequent discrepancies between self-perception and objective sleep measurements reported in AUD (Angarita et al., 2016), as also frequently reported in aging (Nguyen-Michel et al., 2015; Van Den Berg et al., 2008) and neurodegenerative diseases (Hita-Yañez et al., 2013; Most et al., 2012). The rarity of sleep complaint in KS patients is in agreement with their "without complaints appearance" (Walvoort et al., 2016) and may be explained by their cognitive deficits and/or impaired insight that affect their ability to recognize and report problems in self-evaluation questionnaires (Arts et al., 2017; Walvoort et al., 2016). Anosognosia is indeed a specific clinical feature of KS and reflects the most severe form of impaired self-awareness, 
defined as the inability to accurately estimate one's functional capacity (Prigatano, 2009). It is frequently observed in amnesic patients with associated executive dysfunction (Arts et al., 2017; Shimamura and Squire, 1986).

Some of the recently detoxified AUD patients presented a profile of executive dysfunction as well as macrostructural and microstructural brain abnormalities similar to those observed in KS patients. These patients with severe brain dysfunction, sometimes considered at risk of developing KS (Pitel et al., 2012, 2007; Segobin et al., 2015), did not complain about their sleep. Compared to AUD patients with sleep complaint, these patients presented more severe alterations in fronto-temporal regions and specific damage in the frontal-subcortical tracts. Besides, executive impairments were not found in AUD patients with sleep complaint. These findings suggest a key role of the fronto-temporal network and executive functions in subjective assessment of sleep quality. The evaluation of sleep quality using the PSQI is a complex cognitive task that requires a self-interpretation of internal and physical states, which in turn implies having efficient executive functions to judge both sleep quantity (includes evaluating parameters like total sleep time, sleep latency, number of awakenings, among others) and subjective aspects of sleep quality such as feeling tired or daytime sleepiness (Buysse et al., 1989). Executive impairments result in self-awareness deficits (Goldstein et al., 2009) related to damage within the frontal cortex, especially the dorsolateral (Schmitz, Kawahara-Baccus, \& Johnson, 2004; Shany-Ur et al., 2014) and medial parts of the prefrontal cortex (Fleming \& Dolan, 2012; Schmitz \& Johnson, 2007). Previous studies have reported altered self-awareness in AUD patients, who tend to underestimate their daily alcohol consumption (Lincoln et al., 2011) and cognitive deficits (Kornreich, 2002; Le Berre et al., 2010; Walvoort et al., 2016). In the present study, AUD patients with executive dysfunction and lower gray matter volume in the dorsolateral and medial parts of the prefrontal cortex as well as lower WM integrity in fibers connecting fronto-subcortical regions may thus not be cognitively able to accurately estimate their sleep. It is also worth noting that the group of AUD patients without sleep complaint is highly heterogeneous (figure 2B) and potentially consisted of two sub-groups of patients: one that would be similar to HC or complaint AUD regarding brain structure and function while the other would be similar to KS patients (Parsons, 1998; Pitel et al., 2012, 2007; 
Segobin et al., 2015). The complaint AUD group is more homogeneous since it mainly includes patients with preserved performance and brain measures.

410 The thalamus has been shown to play a crucial role in self-awareness (Shany-Ur et al., 2014) and may 411 also be implicated in self-reported sleep quality. This subcortical structure is known to be affected by 412 chronic and excessive alcohol consumption, with graded effects in thalamic volume from AUD to KS 413 patients (Pitel et al., 2012). Interestingly, while AUD patients with sleep complaint have thalamic 414 volumes significantly different from those of KS patients, the thalamic shrinkage in patients without 415 sleep complaint is similar to that of KS patients. The thalamus being a key node of the Papez circuit involved in episodic memory, one would expect AUD patients without sleep complaint to perform on par with KS patients on the episodic memory task. Conversely, in line with the diagnosis, KS patients were impaired in episodic memory compared with both HC and the two subgroups of AUD, who did not differ from each other. Taken together, these findings suggest that the contribution of the thalamus in self-reported sleep quality may not be related to the involvement of episodic memory abilities, contrary to our hypothesis. Rather, several subcortical regions, including the thalamus, "subserve transforming lower-level interoceptive bodily sensations and representations of self into higher-level self-referential mental representations" (Shany-Ur et al., 2014). AUD patients with severe thalamic abnormalities may be unable to accurately perceive and update current physical states, resulting in the absence of sleep complaint.

One potential limitation of the present study is the absence of objective sleep measures by polysomnography, generally not available in clinical practice. Even though it was not the objective of the present study, it would allow determining whether patients without sleep complaint do present objective sleep disturbances. Further studies combining both objective and subjective sleep measures as well as neuropsychological and multimodal neuroimaging examinations are under way to confirm

431 the proposed cognitive and brain mechanisms underlying sleep perception in AUD and KS patients.

\section{CONCLUSION}

Taken together, our data contribute to a better understanding of self-reported sleep quality in recently detoxified AUD patients, by incorporating new insights from neuropsychological and neuroimaging 
examinations. Given the high prevalence of sleep complaint in AUD patients (Angarita et al., 2016; Chakravorty et al., 2016), the use of a sleep questionnaire in clinical practice should not be abandoned since it reflects the subjective perception of mental states and feelings on which most alcohol treatments are proposed. However, sleep questionnaires should be employed and interpreted with caution with AUD patients presenting executive dysfunction. A neuropsychological assessment of

440 alcohol-related cognitive deficits is thus a crucial step in the treatment of AUD patients early in

441 abstinence. In patients who are cognitively unable to complain, sleep problems would be neglected

442 under a clinical setting and therefore remain untreated. Such a situation would worsen sleep-related

443 clinical consequences in AUD such as increased mood disturbances (Zhabenko et al., 2012), impair

444 their overall quality of life and likely trigger relapse (Brower, 2003), hence defeating the purpose of 445 their initial treatment.

\section{ACKNOWLEDGMENTS}

448 The authors are grateful to the Cyceron MRI staff members for their help with patients and imaging

449 examination acquisition, Claire André, Nicolas Cabé and Angéline Maillard for their helpful 450 comments on the manuscript. We would also like to thank all the participants for their implication in 451 this study. 


\section{REFERENCES}

American Psychiatric Association (2013) American Psychiatric Association, 2013. Diagnostic and statistical manual of mental disorders (5th ed.), American Journal of Psychiatry.

American Psychiatric Association (APA) (2000) Diagnostic and Statistical Manual of Mental Disorders, Fourth Edition, Text Revision (DSM-IV-TR), American Psychiatric Association. Arlington, VA, Am. Psychiatr. Assoc.

Angarita GA, Emadi N, Hodges S, Morgan PT (2016) Sleep abnormalities associated with alcohol, cannabis, cocaine, and opiate use : a comprehensive review. Addict Sci Clin Pract 1-17.

Arts NJ, Walvoort SJ, Kessels RPC (2017) Korsakoff' s syndrome : a critical review. Neuropsychiatr Dis Treat 13:2875-2890.

Beck AT, Ward CH, Mendelson M, Mock J, Erbaugh J (1961) An inventory for measuring depression. Arch Gen Psychiatry 4:561-571.

Brower KJ (2003) Insomnia, alcoholism and relapse. Sleep Med Rev 7:523-539.

Brower KJ (2001) Alcohol's Effects on Sleep in Alcoholics. Alcohol Res Heal 25:110-125.

Buysse DJ, Reynolds CF, Monk TH, Berman SR, Kupfer DJ, III CFR, Monk TH, Berman SR, Kupfer DJ (1989) The Pittsburgh Sleep Quality Index: a new instrument for psychiatric practice and research. Psychiatry Res 28:193-213.

Chakravorty S, Chaudhary NS, Brower KJ (2016) Alcohol Dependence and Its Relationship With Insomnia and Other Sleep Disorders. Alcohol Clin Exp Res 40:2271-2282.

Cianchetti C, Corona S, Foscoliano M, Scalas F, Sannio-Fancello G (2005) Modified Wisconsin Card Sorting Test: Proposal of a supplementary scoring method. Arch Clin Neuropsychol 20:555-558.

Cushman PJ, Forbes R, Lerner W, Stewart M (1985) Alcohol withdrawal syndromes: clinical management with lofexidine. Alcohol Clin Exp Res 9:103-108.

Fleming SM, Dolan RJ (2012) The neural basis of metacognitive ability. Philos Trans R Soc Lond B Biol Sci 367:1338-49. 
Folstein MF, Folstein SE, McHugh PR (1975) “Mini-mental state.” J Psychiatr Res 12:189-198.

Gache P, Michaud P, Landry U, Accietto C, Arfaoui S, Wenger O, Daeppen J-B (2005) The Alcohol Use Disorders Identification Test (AUDIT) as a Screening Tool for Excessive Drinking in Primary Care: Reliability and Validity of a French Version. Alcohol Clin Exp Res 29:20012007.

Goldstein RZ, Craig AD (Bud), Bechara A, Garavan H, Childress AR, Paulus MP, Volkow ND (2009) The Neurocircuitry of Impaired Insight in Drug Addiction. Trends Cogn Sci 13:372-380.

Hita-Yañez E, Atienza M, Cantero JL (2013) Polysomnographic and Subjective Sleep Markers of Mild Cognitive Impairment. Sleep 36:1327-1334.

Jenkinson M, Bannister P, Brady M, Smith S (2002) Improved optimisation for the robust and accurate linear registration and motion correction of brain images. Neuroimage 17:825-841.

Kornreich C (2002) Impaired emotional facial expression recognition is associated with interpersnal problems in alcoholism. Alcohol Alcohol 37:394-400.

Lairie M, Pottier M (1979) Quelques remarques à propos du sommeil dans le syndrome de Korsakoff. EEG Neurophysiol 9:277-285.

Le Berre A-P, Pinon K, Vabret F, Pitel AL, Allain P, Eustache F, Beaunieux H (2010) Study of metamemory in patients with chronic alcoholism using a feeling-of-knowing episodic memory task. Alcohol Clin Exp Res 34:1888-98.

Lincoln R, Rosenthal CF, Malte CA, Simpson T (2011) A pilot study of memory impairment associated with discrepancies between retrospective and daily recall of alcohol consumption. Am J Addict 20:568-574.

Maquet P, Péters J-M, Aerts J, Delfiore G, Degueldre C, Luxen A, Franck G (1996) Functional neuroanatomy of human rapid-eye-movement sleep and dreaming. Nature 383:163-166.

Martin PR, Loewenstein RJ, Kaye WH, Ebert MH, Weingartner H, Gillin JC (1986) Sleep EEG in Korsakoff's psychosis and Alzheimer's disease. Neurology 36:411-411. 
Most EIS, Aboudan S, Scheltens P, Van Someren EJW (2012) Discrepancy between subjective and objective sleep disturbances in early-and moderate-stage alzheimer disease. Am J Geriatr Psychiatry 20:460-467.

Murphy M, Riedner BA, Huber R, Massimini M, Ferrarelli F, Tononi G (2009) Source modeling sleep slow waves. Proc Natl Acad Sci 106:1608-1613.

Nguyen-Michel VH, Lévy PP, Pallanca O, Kinugawa K, Banica-Wolters R, Sebban C, Mariani J, Fournier E, Arnulf I (2015) Underperception of naps in older adults referred for a sleep

Oishi K, Faria A, Van Zijl P, S M (2011) MRI atlas of human white matter. Academic.

Oscar-Berman M, Valmas MM, Sawyer KS, Ruiz SM, Luhar RB, Gravitz ZR (2014) Profiles of impaired, spared, and recovered neuropsychologic processes in alcoholism In: Handbook of

Parsons OA (1998) Neurocognitive Deficits in Alcoholics and Social Drinkers: A Continuum?

Pitel, Beaunieux H, Witkowski T, Vabret F, de la Sayette V, Viader F, Desgranges B, Eustache F 
Prigatano GP (2009) Anosognosia: Clinical and ethical considerations. Curr Opin Neurol 22:606-611.

Rinn W, Desai N, Rosenblatt H, Gastfriend DR (2002) Addiction denial and cognitive dysfunction: a preliminary investigation. J Neuropsychiatry Clin Neurosci 14:52-57.

Rueckert D, Sonoda LI, Hayes C, Hill DL, Leach MO, Hawkes DJ (1999) Nonrigid registration using free-form deformations: application to breast MR images. IEEE Trans Med Imaging 18:712-21.

Schabus M, Dang-Vu TT, Albouy G, Balteau E, Boly M, Carrier J, Darsaud A, Degueldre C, Desseilles M, Gais S, Phillips C, Rauchs G, Schnakers C, Sterpenich V, Vandewalle G, Luxen A, Maquet P (2007) Hemodynamic cerebral correlates of sleep spindles during human non-rapid eye movement sleep. Proc Natl Acad Sci 104:13164-13169.

Schmitz TW, Johnson SC (2007) Relevance to self: A brief review and framework of neural systems underlying appraisal. Neurosci Biobehav Rev 31:585-596.

Schmitz TW, Kawahara-Baccus TN, Johnson SC (2004) Metacognitive evaluation, self-relevance, and the right prefrontal cortex. Neuroimage.

Segobin S, Ritz L, Lannuzel C, Boudehent C, Vabret F, Eustache F, Beaunieux H, Pitel AL (2015) Integrity of white matter microstructure in alcoholics with and without Korsakoff's syndrome. Hum Brain Mapp 36:2795-2808.

Sexton CE, Storsve AB, Walhovd KB, Johansen-Berg H, Fjell AM (2014) Poor sleep quality is associated with increased cortical atrophy in community-dwelling adults. Neurology 83:967-73.

Sexton CE, Zsoldos E, Filippini N, Griffanti L, Winkler A, Mahmood A, Allan CL, Topiwala A, Kyle SD, Spiegelhalder K, Singh-Manoux A, Kivimaki M, Mackay CE, Johansen-Berg H, Ebmeier KP (2017) Associations between self-reported sleep quality and white matter in communitydwelling older adults: A prospective cohort study. Hum Brain Mapp 38:5465-5473.

Shany-Ur T, Lin N, Rosen HJ, Sollberger M, Miller BL, Rankin KP (2014) Self-awareness in neurodegenerative disease relies on neural structures mediating reward-driven attention. Brain $137: 2368-2381$. 
Shimamura AP, Squire LR (1986) Memory and Metamemory. A Study of the Feeling-of-Knowing Phenomenon in Amnesic Patients. J Exp Psychol Learn Mem Cogn 12:452-460.

Smith SM, Jenkinson M, Woolrich MW, Beckmann CF, Behrens TEJ, Johansen-Berg H, Bannister PR, De Luca M, Drobnjak I, Flitney DE, Niazy RK, Saunders J, Vickers J, Zhang Y, De Stefano N, Brady JM, Matthews PM (2004) Advances in functional and structural MR image analysis and implementation as FSL. Neuroimage 23:S208-S219.

Stein MD, Friedmann PD (2005) Disturbed sleep and its relationship to alcohol use. Subst Abus 26:113.

Stroop JR (1935) Studies of interference in serial verbal reactions. J Exp Psychol 18:643-662.

Van Den Berg JF, Van Rooij FJA, Vos H, Tulen JHM, Hofman A, Miedema HME, Neven AK, Tiemeier H (2008) Disagreement between subjective and actigraphic measures of sleep duration in a population-based study of elderly persons. J Sleep Res 17:295-302.

Van der Linden M, Coyette F, Poitrenaud J, Kalafat M, Calicis F, Wyns C, Adam S (2004) L'épreuve de rappel libre / rappel indicé à 16 items (RL/RI-16) In: L'évaluation Des Troubles de La Mémoire : Présentation de Quatre Tests de Mémoire Épisodique Avec Leur Étalonnage , pp 2542. Marseille.

Walvoort SJW, van der Heijden PT, Wester AJ, Kessels RPC, Egger JIM (2016) Self-awareness of cognitive dysfunction: Self-reported complaints and cognitive performance in patients with alcohol-induced mild or major neurocognitive disorder. Psychiatry Res 245:291-296.

Wechsler D (1997) Wechsler Memory Scale- (Third Ed.). Psychol Corp.

Zahr NM (2014) Structural and microstructral imaging of the brain in alcohol use disorders, 1st ed, Handbook of Clinical Neurology. Elsevier B.V.

Zhabenko N, Wojnar M, Brower KJ (2012) Prevalence and Correlates of Insomnia in a Polish Sample of Alcohol-Dependent Patients. Alcohol Clin Exp Res 36:1600-1607. 


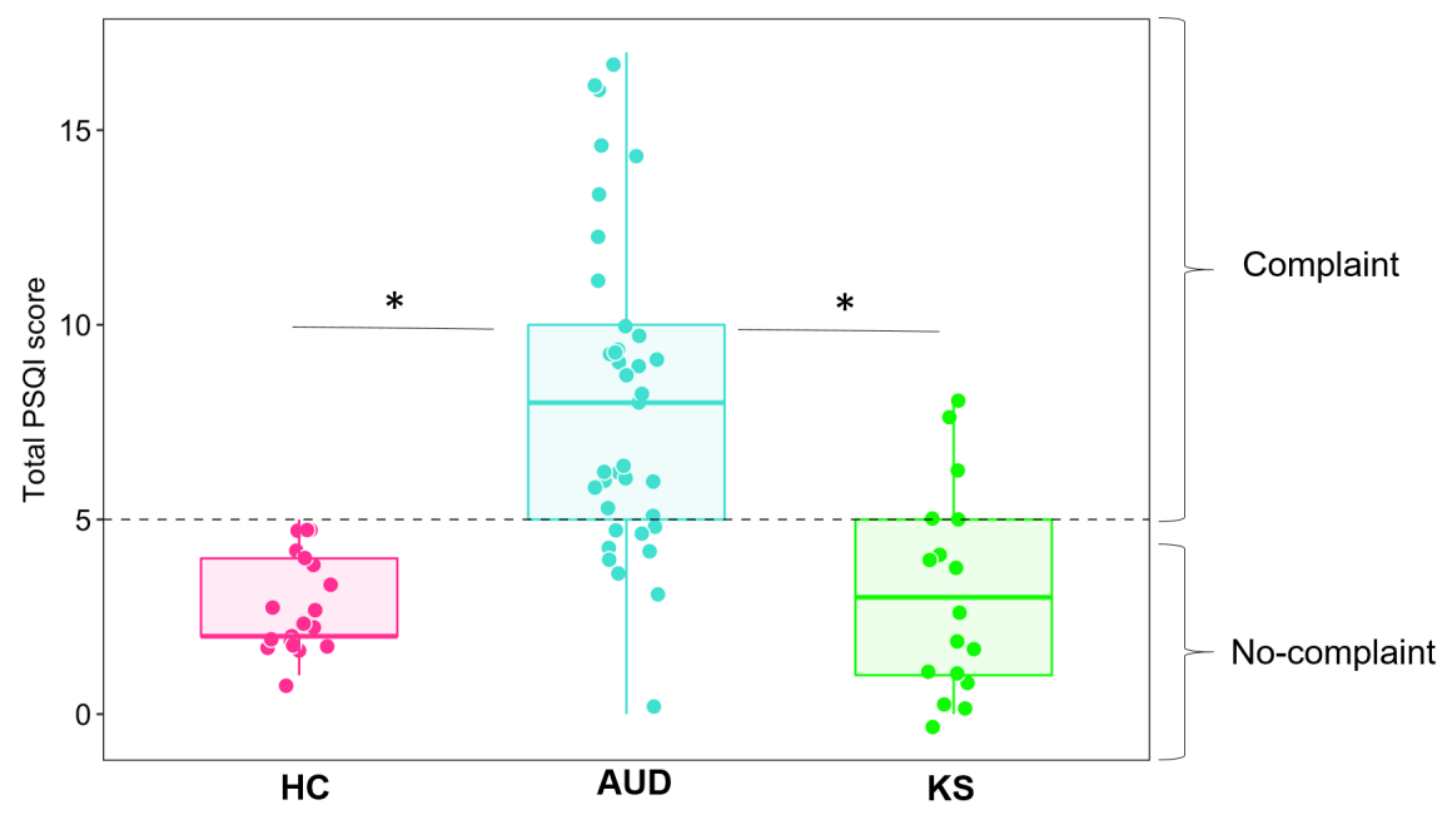

583

584 Figure 1: Prevalence of sleep complaint in HC, AUD and KS patients

585 The dotted line represents the cut-off score (5) of the PSQI, which indicates the presence of a sleep 586 complaint. For each boxplot, the median is represented by the bold line. HC = healthy controls; AUD

587 = patients with Alcohol Use Disorder without Korsakoff's syndrome; KS = patients with Alcohol Use 588 Disorder with Korsakoff ‘s Syndrome. *:p $<0.05$ (Tukey’s tests).

589

590 

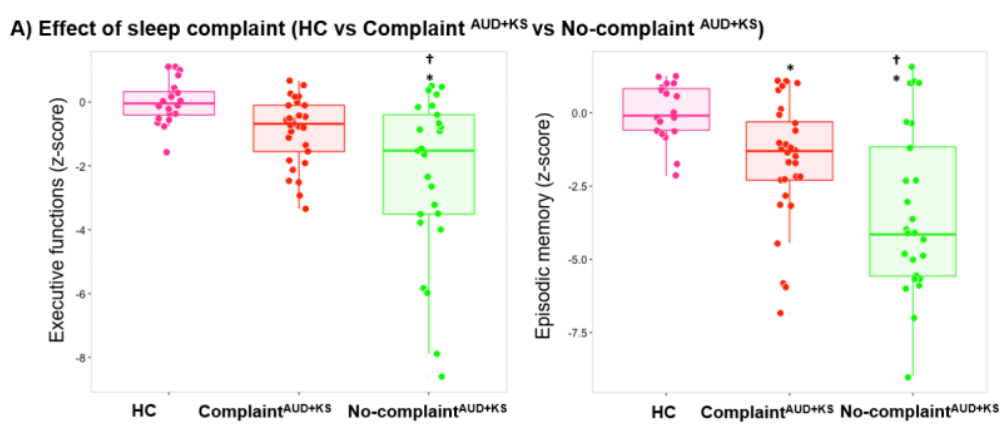

B) Effect of diagnosis
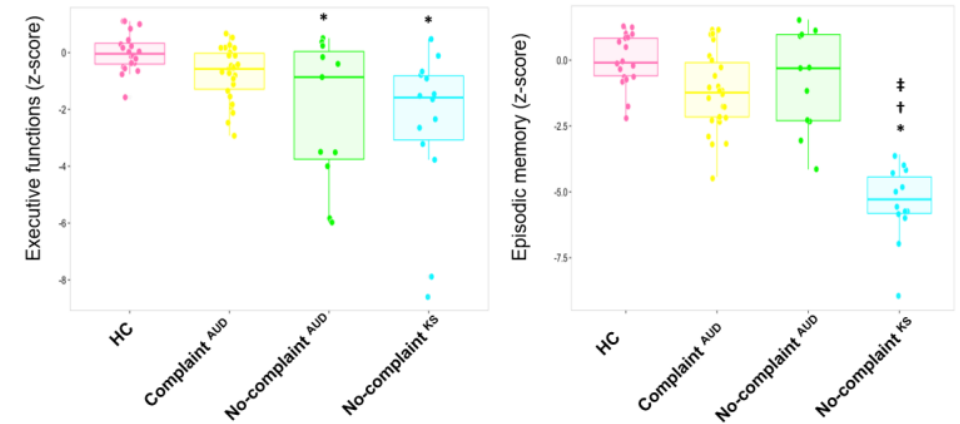

593 Figure 2: Executive and episodic memory performance in controls and patients according to the

$594 \quad$ sleep complaint (A) and diagnosis (B)

595 This figure shows executive (left) and memory (right) z-scores. * : significant difference compared to

$596 \mathrm{HC}(\mathrm{p}<.05) ; \uparrow:$ significant difference compared to complaint $^{\mathrm{AUD}}(\mathrm{p}<.05) ; \ddagger$ : significant difference

597 compared to no-complaint ${ }^{\mathrm{AUD}}(\mathrm{p}<.05)$. Tukey's tests. 


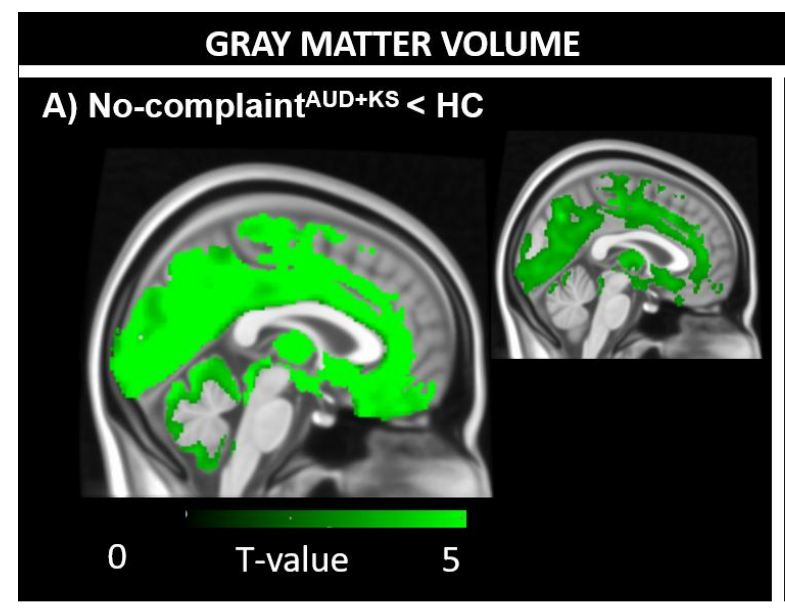

\section{WHITE MATTER INTEGRITY}
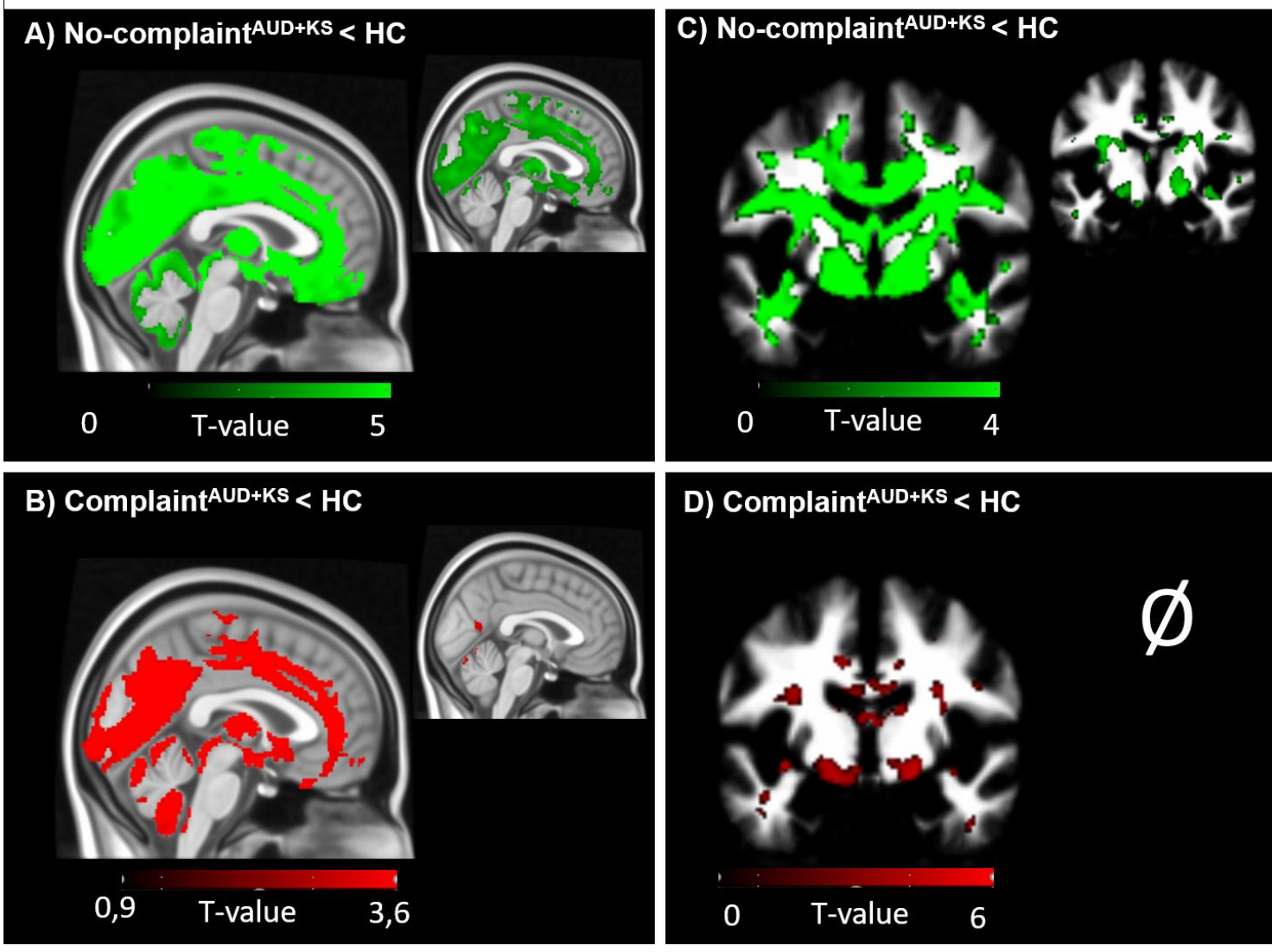

D) Complaint ${ }^{A U D+K S}<$ HC

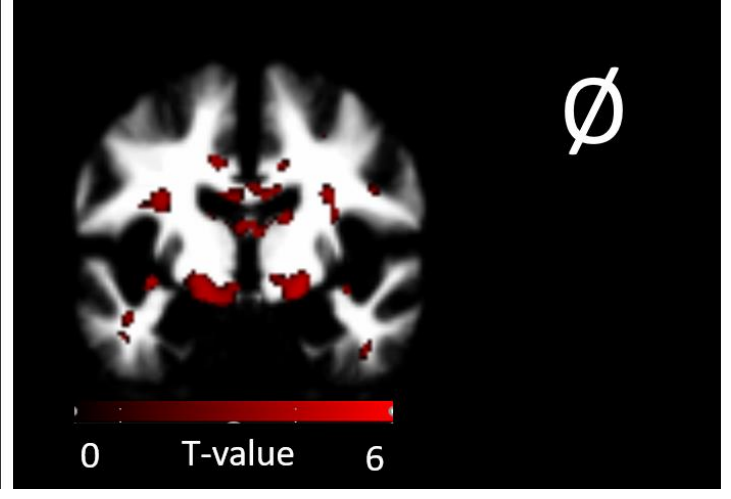

601

602 Figure 3: Structural brain abnormalities in patients with and without sleep complaint compared with controls

A: Lower gray matter volumes (left) and altered white matter integrity (right) in no-complaint ${ }^{\mathrm{AUD}+\mathrm{KS}}$ compared to HC. B: Lower gray matter volumes (left) and altered white matter integrity (right) in 606 complaint $^{\mathrm{AUD}+\mathrm{KS}}$ compared to $\mathrm{HC}$. We used a $\mathrm{p}$ value cutoff of $\mathrm{p}<0.001$ uncorrected (larger images)

607 but also display the results using a restrictive $\mathrm{p}<0.05$ corrected for family-wise error (smaller images)

608 to highlight the most significant regions. For D) No significant results at $p<0.05$ FWE. Cluster size:

$609>60$ voxels.

610 

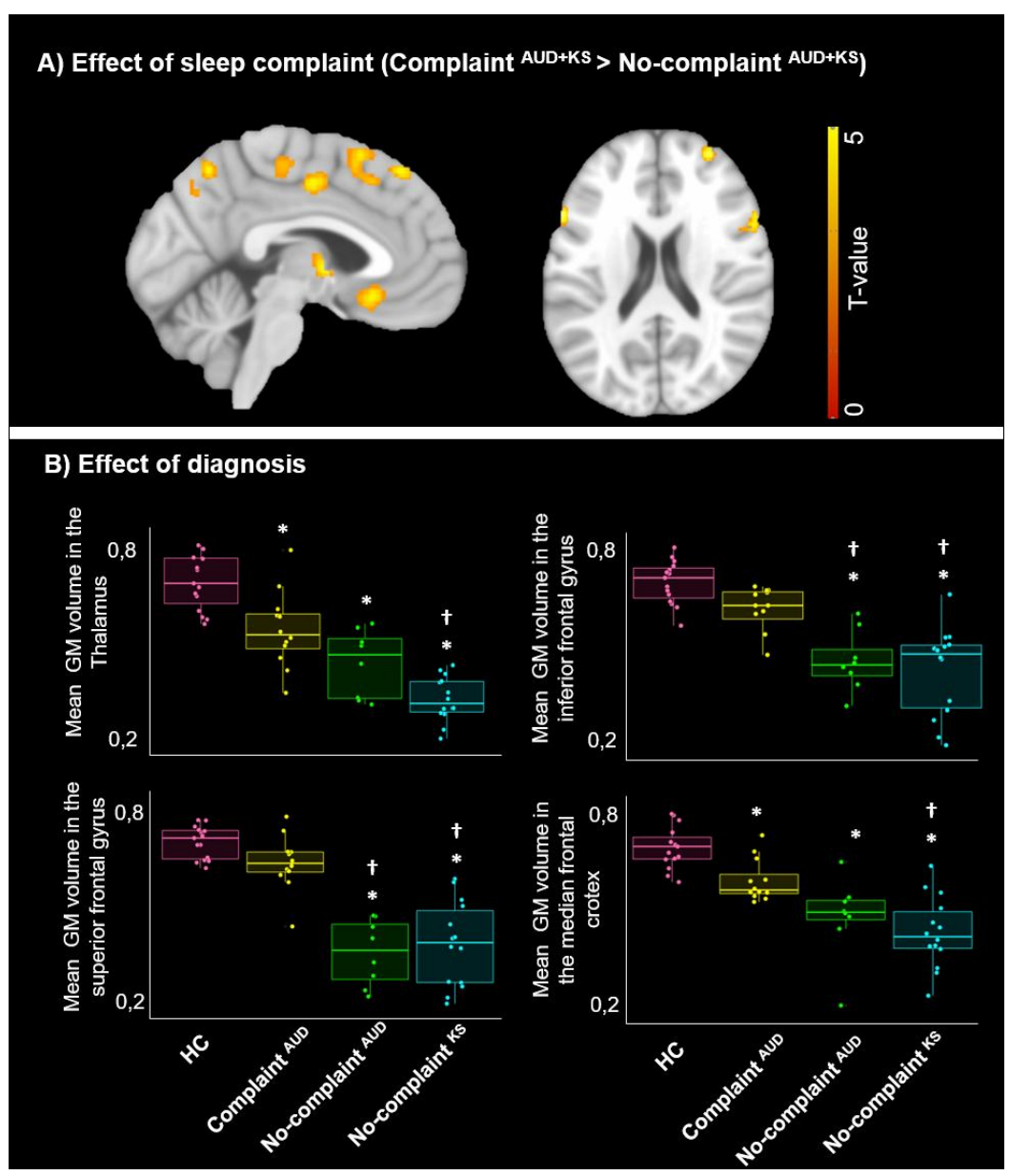

612 Figure 4: Gray matter volume in controls and patients according to the sleep complaint (A) and

\section{3 diagnosis (B)}

614 A: voxel by voxel analysis, $p<0.001$ uncorrected, $k=60$. B: example of regions of interest extracted

615 from the previous analysis. * : significant difference compared to $\mathrm{HC}(\mathrm{p}<.05) ; \dagger$ : significant 616 difference compared to complaint ${ }^{\mathrm{AUD}}(\mathrm{p}<.05)$. Tukey's tests. 

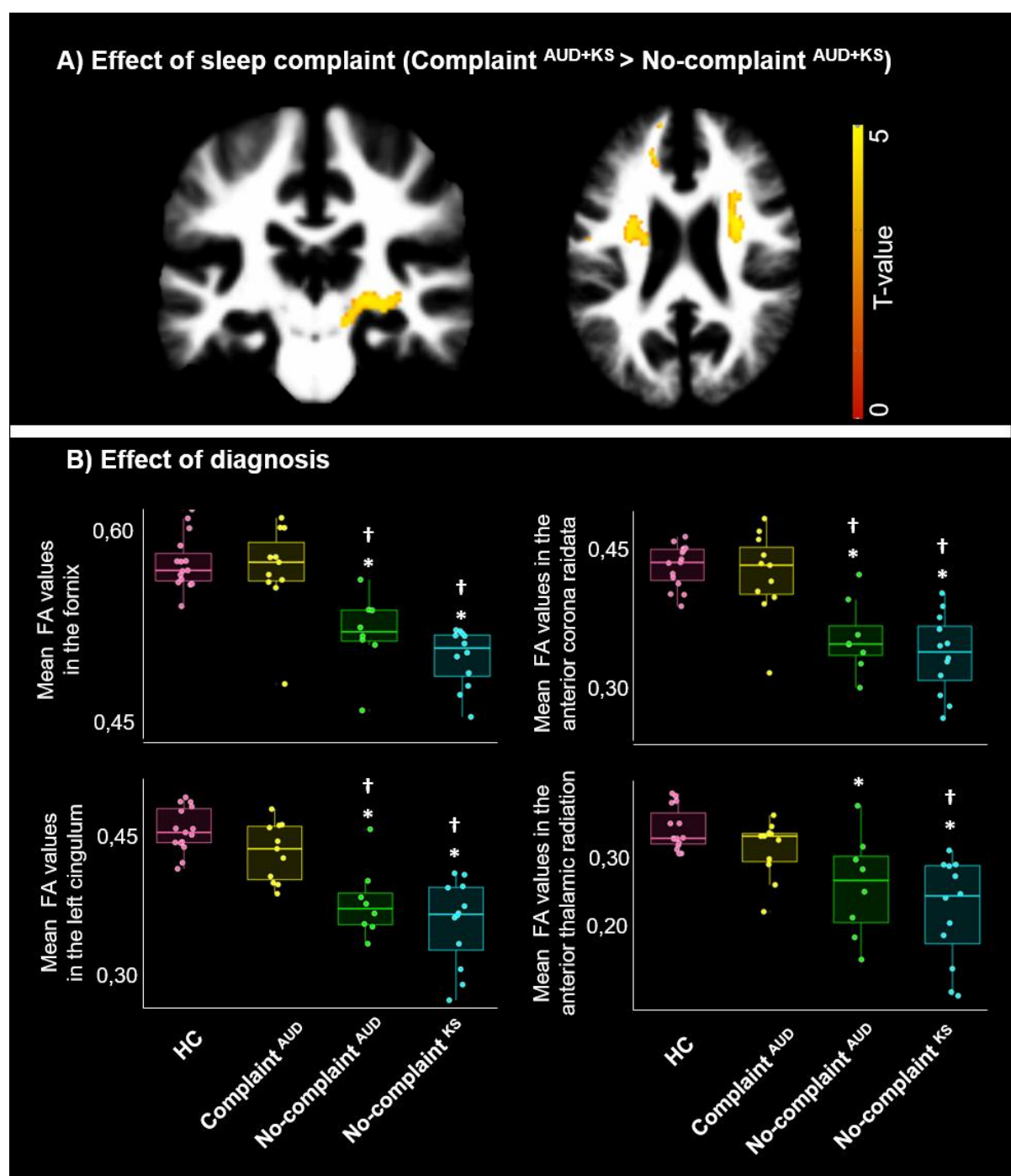

618

619 Figure 5: White matter integrity in controls and patients according to the sleep complaint (A) and diagnosis (B)

621 A: voxel by voxel analysis, $\mathrm{p}<0.001$ uncorrected, $\mathrm{k}=60$. B. example of regions of interest extracted

622 from the previous analysis. *: significant difference compared to $\mathrm{HC}(\mathrm{p}<.05)$; $\uparrow$ : significant difference

to

complaint $^{\mathrm{AUD}}$

$(\mathrm{p}<.05)$.

Tukey's

test 
TABLE 1: DEMOGRAPHICAL AND CLINICAL DESCRIPTION OF THE HEALTHY CONTROLS (HC), ALCOHOL USE DISORDER PATIENTS WITHOUT KORSAKOFF'S SYNDROME (AUD) AND ALCOHOL USE DISORDER PATIENTS WITH KORSAKOFF'S SYNDROME (KS

\begin{tabular}{|c|c|c|c|c|}
\hline & $\begin{array}{c}\mathrm{HC} \\
(\mathbf{N}=20)\end{array}$ & $\begin{array}{c}\text { AUD } \\
(\mathbf{N}=\mathbf{3 7})\end{array}$ & $\begin{array}{c}\mathbf{K S} \\
(\mathbf{N}=17)\end{array}$ & Post-hoc comparisons \\
\hline Age & $\begin{array}{c}42.50 \pm 5.94 \\
{[31 ; 53]}\end{array}$ & $\begin{array}{c}45.59 \pm 9.21 \\
{[32 ; 65]}\end{array}$ & $\begin{array}{c}56.41 \pm 4.79 \\
{[49 ; 67]}\end{array}$ & $(\mathrm{HC}=\mathrm{AUD})>\mathrm{KS}$ \\
\hline Gender. male \% & $80 \%$ & $70.3 \%$ & $41.2 \%$ & $(\mathrm{HC}=\mathrm{AUD})>\mathrm{KS}$ \\
\hline $\begin{array}{l}\text { Education } \\
\text { schooling) }\end{array}$ (years $\quad$ of & $\begin{array}{c}12.20 \pm 2.01 \\
{[9 ; 15]}\end{array}$ & $\begin{array}{c}11.43 \pm 1.57 \\
{[9 ; 15]}\end{array}$ & $\begin{array}{c}10.65 \pm 2.34 \\
{[8 ; 15]}\end{array}$ & $\begin{array}{l}\mathrm{HC}=\mathrm{AUD} ; \mathrm{HC}> \\
\mathrm{KS} ; \mathrm{AUD}=\mathrm{KS}\end{array}$ \\
\hline BMI & $\begin{array}{c}26.53 \pm 6.73 \\
{[19.53 ; 48.88]}\end{array}$ & $\begin{array}{c}24.23 \pm 4.61 \\
{[16.02 ; 39.84]}\end{array}$ & $\begin{array}{c}23.77 \pm 5.45 \\
{[15.94 ; 35.42]}\end{array}$ & $\mathrm{HC}=\mathrm{AUD}=\mathrm{KS}$ \\
\hline BDI & $\begin{array}{c}3.25 \pm 3.47 \\
{[0 ; 14]}\end{array}$ & $\begin{array}{c}13.11 \pm 7.64 \\
{[2 ; 28]}\end{array}$ & $\begin{array}{c}7.05 \pm 6.33 \\
{[0 ; 19]}\end{array}$ & $(\mathrm{HC}=\mathrm{KS})<\mathrm{AUD}$ \\
\hline STAI A & $\begin{array}{c}26.05 \pm 6.68 \\
{[20 ; 47]}\end{array}$ & $\begin{array}{c}32.32 \pm 35 \\
{[20 ; 61]}\end{array}$ & $\begin{array}{c}35 \pm 13.99 \\
{[20 ; 66]}\end{array}$ & $\mathrm{HC}=\mathrm{AUD}=\mathrm{KS}$ \\
\hline STAI B & $\begin{array}{c}32.80 \pm 7.59 \\
{[20 ; 50]}\end{array}$ & $\begin{array}{c}44.22 \pm 12.47 \\
{[28 ; 72]}\end{array}$ & $\begin{array}{c}38.67 \pm 10.03 \\
{[24 ; 57]}\end{array}$ & $\begin{array}{l}\mathrm{HC}<\mathrm{AUD} ; \mathrm{HC}= \\
\mathrm{KS} ; \mathrm{AUD}=\mathrm{KS}\end{array}$ \\
\hline AUDIT & $\begin{array}{c}2.7 \pm 1.92 \\
{[0 ; 6]}\end{array}$ & $\begin{array}{c}28.92 \pm 6.22 \\
{[9 ; 40]}\end{array}$ & NA & $\mathrm{HC}<\mathrm{AUD}$ \\
\hline Alcohol use (years) & l & $\begin{array}{c}15.30 \pm 4.06 \\
{[7 ; 32]}\end{array}$ & NA & l \\
\hline $\begin{array}{l}\text { Alcohol misuse (number of } \\
\text { years) }\end{array}$ & l & $\begin{array}{c}16.54 \pm 8.34 \\
{[2 ; 34]}\end{array}$ & NA & l \\
\hline $\begin{array}{l}\begin{array}{l}\text { Alcohol dependence } \\
\text { (number of years) }\end{array} \\
\end{array}$ & l & $\begin{array}{c}8.65 \pm 7.73 \\
{[0 ; 34]}\end{array}$ & NA & l \\
\hline $\begin{array}{l}\text { Daily alcohol consumption } \\
\left.\text { (units }{ }^{\mathrm{a}}\right)\end{array}$ & l & $\begin{array}{c}18.49 \pm 8.82 \\
{[0-39.4]}\end{array}$ & NA & / \\
\hline $\begin{array}{l}\text { Number of previous } \\
\text { detoxifications }\end{array}$ & l & $\begin{array}{c}2.64 \pm 2.21 \\
{[0 ; 11]}\end{array}$ & NA & l \\
\hline Maximum Cushman score & l & $\begin{array}{c}5.33 \pm 2.42 \\
{[0 ; 11]}\end{array}$ & NA & l \\
\hline $\begin{array}{l}\text { Days of sobriety before } \\
\text { inclusion }\end{array}$ & l & $\begin{array}{c}10.5 \pm 3.99 \\
{[4 ; 21]}\end{array}$ & NA & l \\
\hline $\begin{array}{ll}\text { Mini } \quad \text { Mental } & \text { State } \\
\text { Examination (MMSE) } & (/ \mathbf{3 0})\end{array}$ & $\begin{array}{c}29.22 \pm 0.73 \\
{[28 ; 30]}\end{array}$ & $\begin{array}{c}27.17 \pm 2.15 \\
{[21 ; 30]}\end{array}$ & $\begin{array}{c}22.59 \pm 3.75 \\
{[12 ; 27]}\end{array}$ & $\mathrm{HC}>\mathrm{AUD}>\mathrm{KS}$ \\
\hline $\begin{array}{l}\begin{array}{l}\text { Executive } \\
\text { scores) }\end{array} \\
\text { Functions } \quad \text { (z- } \\
\end{array}$ & $\begin{array}{c}0 \pm 0.68 \\
{[-1.57 ; 1.10]}\end{array}$ & $\begin{array}{c}-1.14 \pm 1.66 \\
{[-5.98 ; 0.67]}\end{array}$ & $\begin{array}{l}-2.46 \pm 2.48 \\
{[-8.6 ; 0.48]}\end{array}$ & $\mathrm{HC}>\mathrm{AUD}>\mathrm{KS}$ \\
\hline Episodic Memory (z-scores) & $\begin{array}{c}0 \pm 1 \\
{[-2.15 ; 1.25]}\end{array}$ & $\begin{array}{c}-0.97 \pm 1.57 \\
{[-4.43 ; 1.54]}\end{array}$ & $\begin{array}{c}-5.33 \pm 0.99 \\
{[-6.99 ;-3.57]}\end{array}$ & $\mathrm{HC}>\mathrm{AUD}>\mathrm{KS}$ \\
\hline
\end{tabular}


TABLE 2: DESCRIPTIVE STATISTICS IN THE DIFFERENT SUBGROUPS ACCORDING TO THE SLEEP COMPLAINT

\begin{tabular}{|c|c|c|c|c|c|c|c|}
\hline & \multirow{2}{*}{$\begin{array}{l}\text { HC } \\
n=20\end{array}$} & \multicolumn{3}{|c|}{ No-complaint } & \multicolumn{3}{|c|}{ Complaint } \\
\hline & & $\begin{array}{c}\text { No-Complaint } \\
n=25\end{array}$ & $\begin{array}{c}\text { No- } \\
\text { Complaint }^{\mathrm{AUD}} \\
n=11\end{array}$ & $\begin{array}{c}\text { No-Complaint } \\
n=13\end{array}$ & $\begin{array}{c}\text { Complaint }_{n=29}^{\mathrm{AUD}+\mathrm{KS}} \\
{ }^{\mathrm{n}}\end{array}$ & $\underset{n=26}{\text { Complaint }^{\mathrm{AUD}}}$ & $\begin{array}{c}\text { Complaint }_{n=3} \\
\text { KS }\end{array}$ \\
\hline Age (years) & $\begin{array}{c}42.50 \pm 5.94 \\
{[31-53]}\end{array}$ & $\begin{array}{c}50.68 \pm 9.55 \\
{[34-67]} \\
\end{array}$ & $\begin{array}{c}2.73 \pm 8.16 \\
{[34-61]} \\
\end{array}$ & $\begin{array}{c}56.93 \pm 4.66 \\
{[49-67]}\end{array}$ & $\begin{array}{c}47.55 \pm 9.37 \\
{[32-65]}\end{array}$ & $\begin{array}{c}46.81 \pm 9.51 \\
{[32-65]}\end{array}$ & $\begin{array}{c}54 \pm 5.57 \\
{[49-0]}\end{array}$ \\
\hline Gender. male \% & $80 \%$ & $60 \%$ & $81.81 \%$ & $42.85 \%$ & $62.06 \%$ & $65.38 \%$ & $33.3 \%$ \\
\hline Education (years) & $\begin{array}{c}12.20 \pm 2.01 \\
{[9-15]}\end{array}$ & $\begin{array}{c}11.4 \pm 2.08 \\
{[8-15]}\end{array}$ & $\begin{array}{c}11.78 \pm 1.64 \\
{[9-14]}\end{array}$ & $\begin{array}{c}10.93 \pm 2.33 \\
{[8-15]}\end{array}$ & $\begin{array}{c}11.00 \pm 1.66 \\
{[8-15]}\end{array}$ & $\begin{array}{c}11.32 \pm 1.56 \\
{[9-15]}\end{array}$ & $\begin{array}{c}9.33 \pm 2.3 \\
{[8-12]}\end{array}$ \\
\hline BMI & $\begin{array}{c}26.53 \pm 6.73 \\
{[19.53-48.88]}\end{array}$ & $\begin{array}{c}24.16 \pm 4.63 \\
{[15.94-35.42]}\end{array}$ & $\begin{array}{c}24.07 \pm 2.7 \\
{[19.23-29.97]}\end{array}$ & $\begin{array}{c}23.89 \pm 5.85 \\
{[15.94-35.42]}\end{array}$ & $\begin{array}{l}24.161 \pm 5.09 \\
{[16.02-39.84]}\end{array}$ & $\begin{array}{c}24.30 \pm 5.26 \\
{[16.02-39.84]}\end{array}$ & $\begin{array}{c}23.24 \pm 6.73 \\
{[19.53-46.88]}\end{array}$ \\
\hline BDI & $\begin{array}{c}3.25 \pm 3.47 \\
{[0-14]}\end{array}$ & $\begin{array}{c}9.4 \pm 8.11 \\
{[0-27]}\end{array}$ & $\begin{array}{c}14.73 \pm 8.17 \\
{[4-27]}\end{array}$ & $\begin{array}{c}5.21 \pm 5.22 \\
{[0-15]}\end{array}$ & $\begin{array}{c}12.75 \pm 7.16 \\
{[2-28]} \\
\end{array}$ & $\begin{array}{c}12.42 \pm 7.46 \\
{[2-28]}\end{array}$ & $\begin{array}{c}15.67 \pm 3.05 \\
{[13-19]} \\
\end{array}$ \\
\hline STAI A & $\begin{array}{c}26.05 \pm 6.68 \\
{[20-47]}\end{array}$ & $\begin{array}{c}32 \pm 11.99 \\
{[20-59]}\end{array}$ & $\begin{array}{c}33.09 \pm 13.44 \\
{[20-59]}\end{array}$ & $\begin{array}{l}31 \pm 11 \\
{[20-55]}\end{array}$ & $\begin{array}{c}33.96 \pm 12.37 \\
{[20-66]}\end{array}$ & $\begin{array}{c}32.00 \pm 10.71 \\
{[20-61]}\end{array}$ & $\begin{array}{c}51.00 \pm 15.00 \\
{[36-66]}\end{array}$ \\
\hline STAI B & $\begin{array}{c}32.80 \pm 7.59 \\
{[20-50]}\end{array}$ & $\begin{array}{c}39.65 \pm 10.65 \\
{[24-59]}\end{array}$ & $\begin{array}{c}43.73 \pm 11.31 \\
{[28-59]}\end{array}$ & $\begin{array}{c}35.92 \pm 8.87 \\
{[24-50]}\end{array}$ & $\begin{array}{c}44.96 \pm 12.64 \\
{[28-72]}\end{array}$ & $\begin{array}{c}44.42 \pm 13.13 \\
{[28-72]}\end{array}$ & $\begin{array}{c}49.67 \pm 6.65 \\
{[44-57]}\end{array}$ \\
\hline AUDIT & $\begin{array}{c}2.7 \pm 1.92 \\
{[0-; 6]}\end{array}$ & l & $\begin{array}{c}26.64 \pm 8.23 \\
{[9-39]}\end{array}$ & l & l & $\begin{array}{c}29.92 \pm 4.97 \\
{[16-40]}\end{array}$ & l \\
\hline Alcohol use (years) & l & NA & $\begin{array}{c}14.36 \pm 2.61 \\
{[10-19]}\end{array}$ & NA & NA & $\begin{array}{c}15.69 \pm 4.53 \\
{[7-32]}\end{array}$ & NA \\
\hline $\begin{array}{l}\text { Alcohol misuse (number of } \\
\text { years) }\end{array}$ & l & NA & $\begin{array}{c}18.27 \pm 7.65 \\
{[6-26]}\end{array}$ & NA & NA & $\begin{array}{c}15.81 \pm 8.65 \\
{[2-34]}\end{array}$ & NA \\
\hline $\begin{array}{l}\text { Alcohol dependence } \\
\text { (number of years) }\end{array}$ & l & NA & $\begin{array}{c}9.72 \pm 7.79 \\
{[2-26]}\end{array}$ & NA & NA & $\begin{array}{c}8.16 \pm 7.82 \\
{[0-34]}\end{array}$ & NA \\
\hline $\begin{array}{l}\text { Daily alcohol consumption } \\
\text { (units) }\end{array}$ & l & NA & $\begin{array}{l}19.03 \pm 8.69 \\
{[0-30]}\end{array}$ & NA & NA & $\begin{array}{c}18.23 \pm 9.07 \\
{[2-39.40]}\end{array}$ & NA \\
\hline $\begin{array}{ll}\text { Number of } & \text { previous } \\
\text { detoxifications }\end{array}$ & l & NA & $\begin{array}{c}3.81 \pm 3.21 \\
{[0-11]}\end{array}$ & NA & NA & $\begin{array}{l}2.15 \pm 1.43 \\
{[0-6]}\end{array}$ & NA \\
\hline Maximum Cushman score & l & NA & $\begin{array}{c}5.9 \pm 1.91 \\
{[3-9]}\end{array}$ & NA & NA & $\begin{array}{c}5.11 \pm 2.59 \\
{[0-11]}\end{array}$ & NA \\
\hline $\begin{array}{l}\text { Days of sobriety before } \\
\text { inclusion }\end{array}$ & l & NA & $\begin{array}{c}13.55 \pm 4.15 \\
{[7-21]}\end{array}$ & NA & NA & $\begin{array}{c}9.16 \pm 3.15 \\
{[4-15]}\end{array}$ & NA \\
\hline
\end{tabular}


Table 3: Prevalence, Severity and Nature of THE SleEP COMPlaint ON THE PSQI in HEALTHY CONTROLS (HC), ALCOHOL USE DISORDER PATIENTS WITHOUT KORSAKOFF'S SYNDROME (AUD) AND ALCOHOL USE DISORDER PATIENTS WITH KORSAKOFF'S SYNDROME (KS).

$\begin{array}{lllll}\text { HC } & \text { AUD } & \text { KS } & \text { Statistics }^{a} & \text { Post hoc }\end{array}$ comparisons $^{\mathbf{b}}$

\begin{tabular}{|c|c|c|c|c|c|}
\hline \multicolumn{6}{|l|}{$\begin{array}{l}\text { Total score }(0 \\
\text { to 21) }\end{array}$} \\
\hline $\begin{array}{l}\text { Prevalence } \\
(\text { PSQI >5) }\end{array}$ & $0 \%$ & $70 \%(\mathrm{~N}=26)$ & $17 \%(\mathrm{~N}=3)$ & $\mathrm{X}^{2}=31.19 \mathrm{p}<0.0001$ & $\begin{array}{c}\mathrm{AUD}>\mathrm{KS}= \\
\mathrm{HC}\end{array}$ \\
\hline Severity & $\begin{array}{c}3 \pm 1.21 \\
{[1-5]}\end{array}$ & $\begin{array}{c}8.32 \pm 3.97 \\
{[0-17]}\end{array}$ & $\begin{array}{c}3.35 \pm 2.80 \\
{[0-9]}\end{array}$ & $\mathrm{F}(2.68)=26.63 \mathrm{p}<0.0001$ & $\begin{array}{c}\text { AUD }>\text { KS }= \\
\text { HC }\end{array}$ \\
\hline \multicolumn{6}{|l|}{$\begin{array}{l}\text { Subcomponents } \\
\left(\begin{array}{l}0 \text { to } 3) \\
\end{array}\right.\end{array}$} \\
\hline $\begin{array}{c}\text { Subjective } \\
\text { sleep quality }\end{array}$ & $\begin{array}{c}0.6 \pm 0.5 \\
{[0-1]} \\
\end{array}$ & $\begin{array}{c}1.35 \pm 0.85 \\
{[0-3]}\end{array}$ & $\begin{array}{c}0.52 \pm 0.51 \\
{[0-1]}\end{array}$ & $\mathrm{F}(2.68)=10.98 \mathrm{p}<0.0001$ & $\begin{array}{c}\mathrm{HC}=\mathrm{KS}> \\
\mathrm{AUD}\end{array}$ \\
\hline Sleep latency & $\begin{array}{c}0.6 \pm 0.68 \\
{[0-2]}\end{array}$ & $\begin{array}{c}1.32 \pm 0.94 \\
{[0-3]}\end{array}$ & $\begin{array}{c}0.76 \pm 1.03 \\
{[0-3]}\end{array}$ & $\mathrm{F}(2.68)=5.30 \mathrm{p}=0.007$ & $\begin{array}{c}\mathrm{HC}=\mathrm{KS} \\
\mathrm{HC}<\mathrm{AUD} \\
\mathrm{AUD}=\mathrm{KS}\end{array}$ \\
\hline Sleep duration & $\begin{array}{c}0.6 \pm 0.82 \\
{[0-3]}\end{array}$ & $\begin{array}{c}1.21 \pm 1.05 \\
{[0-3]}\end{array}$ & $\begin{array}{c}0.11 \pm 0.33 \\
{[0-1]}\end{array}$ & $\mathrm{F}(2.68)=8.75 \mathrm{p}=0.0004$ & $\begin{array}{c}\mathrm{HC}=\mathrm{KS} ; \mathrm{HC} \\
=\mathrm{AUD} ; \mathrm{KS}> \\
\text { AUD }\end{array}$ \\
\hline $\begin{array}{l}\text { Habitual sleep } \\
\text { efficiency }\end{array}$ & $\begin{array}{c}0.05 \pm 0.22 \\
{[0-1]}\end{array}$ & $\begin{array}{c}0.70 \pm 1.10 \\
{[0-3]}\end{array}$ & $\begin{array}{c}0.29 \pm 0.58 \\
{[0-2]}\end{array}$ & $\mathrm{F}(2.68)=10.55 \mathrm{p}<0.0001$ & $\begin{array}{c}\mathrm{HC}=\mathrm{KS} \\
\mathrm{HC}<\mathrm{AUD} \\
\mathrm{AUD}=\mathrm{KS}\end{array}$ \\
\hline $\begin{array}{l}\text { Sleep } \\
\text { disturbances }\end{array}$ & $\begin{array}{c}0.85 \pm 0.36 \\
{[0-1]}\end{array}$ & $\begin{array}{c}1.64 \pm 0.78 \\
{[0-3]}\end{array}$ & $\begin{array}{c}0.76 \pm 0.56 \\
{[0-2]}\end{array}$ & $\mathrm{F}(2.68)=13.48 \mathrm{p}<0.0001$ & $\begin{array}{c}\mathrm{HC}=\mathrm{KS}> \\
\mathrm{AUD}\end{array}$ \\
\hline $\begin{array}{l}\text { Use of } \\
\text { sleeping } \\
\text { medication }\end{array}$ & $\begin{array}{c}0.05 \pm 0.22 \\
{[0-1]}\end{array}$ & $\begin{array}{c}0.97 \pm 1.38 \\
{[0-3]}\end{array}$ & $\begin{array}{c}0.52 \pm 1.17 \\
{[0-3]}\end{array}$ & $\mathrm{F}(2.68)=4.36 \mathrm{p}=0.01$ & $\begin{array}{c}\mathrm{HC}=\mathrm{KS} \\
\mathrm{HC}<\mathrm{AUD} \\
\mathrm{AUD}=\mathrm{KS}\end{array}$ \\
\hline $\begin{array}{c}\text { Daytime } \\
\text { dysfunction }\end{array}$ & $\begin{array}{c}0.25 \pm 0.44 \\
{[0-1]}\end{array}$ & $\begin{array}{c}1.10 \pm 0.77 \\
{[0-3]}\end{array}$ & $\begin{array}{c}0.35 \pm 0.78 \\
{[0-3]}\end{array}$ & $\mathrm{F}(2.68)=10.99 \mathrm{p}<0.0001$ & $\begin{array}{c}\mathrm{HC}=\mathrm{KS}> \\
\text { AUD }\end{array}$ \\
\hline \multicolumn{6}{|l|}{$\begin{array}{l}\text { Quantitative } \\
\text { data }\end{array}$} \\
\hline $\begin{array}{l}\text { Sleep duration } \\
\text { (min) }\end{array}$ & $\begin{array}{l}447 \pm 49.53 \\
{[360-510]}\end{array}$ & $\begin{array}{c}397.02 \pm 107.37 \\
{[180-660]}\end{array}$ & $\begin{array}{c}499.41 \pm 71.10 \\
{[420-720]}\end{array}$ & $\mathrm{F}(2,68)=7.57 \mathrm{p}=0.001$ & $\begin{array}{c}\mathrm{HC}=\mathrm{KS} ; \mathrm{HC} \\
=\mathrm{AUD} ; \mathrm{KS}> \\
\text { AUD }\end{array}$ \\
\hline $\begin{array}{l}\text { Sleep latency } \\
\text { (min) }\end{array}$ & $\begin{array}{c}14.75 \pm 9.38 \\
{[5-30]}\end{array}$ & $\begin{array}{c}26.27 \pm 25.88 \\
{[0-120]}\end{array}$ & $\begin{array}{c}22.5 \pm 15.76 \\
{[7.5-60]}\end{array}$ & $\mathrm{F}(2,68)=3.76 \mathrm{p}=0.03$ & $\begin{array}{c}\mathrm{HC}=\mathrm{AUD}= \\
\mathrm{KS}\end{array}$ \\
\hline $\begin{array}{l}\text { Sleep efficiency } \\
(\%)\end{array}$ & $\begin{array}{c}94.61 \pm 5.33 \\
{[82.35-} \\
100] \\
\end{array}$ & $\begin{array}{l}84.24 \pm 16.58 \\
{[36.36-100]}\end{array}$ & $\begin{array}{c}90.67 \pm 7.59 \\
{[77.77-100]}\end{array}$ & $\mathrm{F}(2,68)=8.22 \mathrm{p}=0.0006$ & $\begin{array}{c}\mathrm{HC}=\mathrm{KS} ; \mathrm{HC} \\
>\mathrm{AUD} ; \mathrm{AUD} \\
\quad=\mathrm{KS}\end{array}$ \\
\hline
\end{tabular}




\section{TABLE LEGENDS}

Table 1: Demographical and clinical description of the healthy controls (HC), alcohol use disorder patients without Korsakoff's syndrome (AUD) and alcohol use disorder patients with Korsakoff's syndrome (KS).

Mean \pm Standard Deviation and range [minimum; maximum] are reported. BMI= Body Mass Index; $\mathrm{BDI}=$ Beck Depression Inventory; STAI $=$ State-Trait Anxiety Inventory; AUDIT $=$ Alcohol Use Disorders Identification Test. NA: not available $;{ }^{\mathrm{a}}$ : an alcohol unit $=10 \mathrm{~g}$ of pure ethanol

\section{Table 2: Descriptive Statistics in the different subgroups according to the sleep complaint}

Mean \pm Standard Deviation and range [minimum; maximum] are reported. BMI= Body Mass Index; BDI $=$ Beck Depression Inventory; STAI $=$ State-Trait Anxiety Inventory; AUDIT $=$ Alcohol Use Disorders Identification Test. NA: not available ; ${ }^{a}$ : an alcohol unit $=10 \mathrm{~g}$ of pure ethanol

Table 3: Prevalence, severity and nature of the sleep complaint on the PSQI in healthy controls (HC), alcohol use disorder patients without Korsakoff's syndrome (AUD) and alcohol use disorder patients with Korsakoff's syndrome (KS).

The prevalence of sleep complaint corresponded to the proportion of participants in each group (HC, AUD, KS) with a PSQI total score $>5$ which is a validated cut-off score indicating poor sleep quality. The severity of sleep complaint corresponded to the mean PSQI total score for each group (HC, AUD, KS) which is to the sum of the seven PSQI subcomponents, ranging from 0 (no sleep complaint) to 21 (major sleep disturbances). Each PSQI subcomponent score ranged from 0 (good) to 3 (poor). For PSQI continuous variables, short sleep duration and low sleep efficiency correspond to higher component scores. ${ }^{a}$ : Data were analyzed using ANCOVAs adjusted for age, sex and body mass index (BMI), except for the frequency of sleep complaint for which we used a $\mathrm{Chi}^{2}$ test. $^{\mathrm{b}}$ : Between-groups comparisons were performed with Tukey's tests corrected for unequal sample size. Mean \pm Standard Deviation and range [minimum-maximum] are reported. 